FEDERAL

RESERVE

BANK of

ST. LOUIS

\section{RESEARCH DIVISION}

Working Paper Series

\title{
U.S. Monetary Policy: A View from Macro Theory
}

\author{
William T. Gavin \\ and \\ Benjamin D. Keen
}

Working Paper 2012-019A

https://doi.org/10.20955/wp.2012.019

July 2012

\section{FEDERAL RESERVE BANK OF ST. LOUIS}

Research Division

P.O. Box 442

St. Louis, MO 63166

The views expressed are those of the individual authors and do not necessarily reflect official positions of the Federal Reserve Bank of St. Louis, the Federal Reserve System, or the Board of Governors.

Federal Reserve Bank of St. Louis Working Papers are preliminary materials circulated to stimulate discussion and critical comment. References in publications to Federal Reserve Bank of St. Louis Working Papers (other than an acknowledgment that the writer has had access to unpublished material) should be cleared with the author or authors. 


\title{
U.S. Monetary Policy: A View from Macro Theory
}

\author{
William T. Gavin \\ Benjamin D. Keen
}

\begin{abstract}
We use a dynamic stochastic general equilibrium model to address two questions about U.S. monetary policy: 1) Can monetary policy elevate output when it is below potential? and 2) Is the zero lower bound a trap? The model's answer to the first question is yes it can, but the effect is only temporary and probably not welfare enhancing. The answer to the second question is more complicated because it depends on policy. It also depends on whether it is the inflation rate or the real interest rate that will adjust over the longer run if the policy rate is held near zero for an extended period. We use the Fisher equation to analyze possible outcomes for situations where the central bank has promised to keep the interest rate near zero for an extended period.
\end{abstract}

Keywords DSGE $\cdot$ Monetary Policy $\cdot$ Output Stabilization $\cdot$ Zero Lower Bound

JEL E31· E42 $\cdot \mathrm{E} 58 \cdot \mathrm{E} 61$

W. Gavin (Corresponding Author)

Federal Reserve Bank of St. Louis, P.O. Box 442, St. Louis, MO 63166;

e-mail:gavin@stls.frb.org

B. Keen

University of Oklahoma, 729 Elm Ave., 329 Hester Hall, Norman, OK 73019

We thank Kevin Kliesen and participants in a workshop at the Bank of Greece and at the 16th International Conference on Macroeconomic Analysis and International Finance for helpful comments. The views expressed in this paper are those of the authors and do not necessarily reflect the views of the Federal Reserve Bank of St. Louis or the Federal Reserve System.

\section{Introduction}

Since the onset of the financial crisis in 2007-2008, U.S. monetary policymakers have taken unprecedented actions, issuing large amounts of base money to rescue both insolvent and illiquid financial institutions. At the time of the crisis, the Fed was not certain whether some financial institutions were insolvent or merely illiquid. The Fed lent funds to these firms under the authority of the Section 13(3) of the Federal Reserve Act which allows the Fed to lend to non-bank institutions in "in unusual and exigent circumstances." One effect of this policy was to satiate the economy with bank reserves and to drive money market interest rates to zero. The amount of excess reserves rose from an average of about $\$ 10$ billion before the crisis to over $\$ 1.6$ trillion by the middle of 2011. The policy rate remains at zero but the use of large-scale asset purchases 
(LSAP) by the Fed is thought to simulate a negative policy rate; that is, it leads to lower long-term rates and is thought to provide the same sort of stimulus to the economy that would occur with a lower policy rate in a normal environment in which the policymaker was not constrained by the zero lower bound (ZLB). This LSAP policy supplements the forward guidance provided by the policy committee. ${ }^{1}$

This attempt to provide more monetary stimulus at the ZLB is motivated by the failure of real GDP to grow fast enough to close an output gap that is estimated to be very large for an economy entering the third year of a recovery. The LSAP and forward guidance policies have been associated with lower long-term rates, but there is little evidence of a measurable effect on aggregate demand.

In this paper, we suppose that the LSAP and forward guidance by the Fed can replicate the policies that would be followed if the money market interest rate were not stuck at zero. A linearized version of a dynamic stochastic general equilibrium (DSGE) model is used to address two questions about U.S. monetary policy: 1) Can an aggressive monetary policy elevate output relative to some baseline path? and 2) Is the zero lower bound a trap? In the linearized version of our DSGE model, the interest rate can be negative and the effects of policy are symmetric and unaffected by the ZLB. ${ }^{2}$

\section{Macroeconomic Theory and Monetary Policy}

The state of the art in macroeconomics has changed dramatically since the 1960s. Models built then had fixed parameters that predicted aggregate outcomes without taking account of how expectations about future policy would affect people's behavior. As late as 1975, the state of the art was an optimal control model with fixed parameters. The model was useful in guiding

\footnotetext{
${ }^{1}$ The Federal Open Market Committee (FOMC) began using forward guidance in 1983 when it included a statement about the Committee's expectations for future changes in the stance of monetary policy. For a history of this early experience, see Thornton and Wheelock (2000). Since December 16, 2008, the FOMC has been more explicit about its intention to keep the federal funds rate at an exceptionally low level using language: “... for some time.” On March 18, 2009 it was strengthened to “... for an extended period.” On August 9, 2011, the language included a calendar date: "at least through mid-2013." And on January 25, 2012 the date was extended “... at least through late 2014."

${ }^{2}$ Eggertsson and Woodford (2003) constrain the interest rate in a linearized DSGE model to be greater than or equal to zero. Adam and Brilli (2006, 2007) and Holden and Paetz (2011) use the constrained linearized model to show that negative shocks are amplified at the ZLB. Braun and Korbler (2011) and Braun, Korbler, and Waki (2012) find that the approximation error in the constrained, linearized model becomes very large at the ZLB. Using an analytical solution to a nonlinear model, they show that macro dynamics at the ZLB resemble standard New Keynesian dynamics. They recommend against using the constrained version of the linearized model.
} 
spaceships to the moon and in developing optimal input policies for manufacturing machines, but it could not predict how policy could achieve macroeconomic stabilization because it did not take account of how people would change their behavior when new policies were introduced.

The first major breakthrough in modern macro theory was the rational expectations revolution in which economists learned how to put forward-looking behavior in the linear IS/LM model. For the policy advisor, an important contribution of this literature was to teach us that we should not use models with backward-looking inflation expectations to perform counterfactual policy simulations.

Once economists realized the insights and benefits from using models in which people formed expectations optimally, it was natural to move to models in which all behavior was assumed to be optimizing. The second major breakthrough, then, was the first DSGE model — the real business cycle (RBC) model developed by Kydland and Prescott (1982). This model begins with households that maximize utility and firms that maximize profits. The single driving process in this model was a stochastic technology factor. The major contribution of this literature was to teach us that some variation in GDP is due to real factors and it is not optimal for policy to try to eliminate all aggregate fluctuations. Another contribution was an extension of the rational expectations lesson - we should not use models with arbitrary behavior rules to perform counterfactual policy simulations.

In the RBC model all markets cleared within a quarter and all agents behaved optimally. When one adds money and inflation to the model, the result is the classical dichotomy - monetary policy can affect nominal variables, but has almost no effect on real output or the unemployment rate. Monetary policy has small real effects - higher inflation acts as a tax on money holdings — but this channel is inconsistent with the standard view of the Phillips curve in which higher inflation will lead, at least temporarily, to higher output.

Many economists, including Robert E. Lucas, Jr., the leader of the rational expectations revolution, had a strong prior view that Milton Friedman was correct in his belief that monetary cycles were an important cause of business cycles. In his Helsinki lectures, Lucas (1987) wrote:

I prefer to pursue the more conventional view that the real effects of policy arise by a very different route from the inflation tax effects we have been discussing, that they arise instead because a monetary contraction has real effects, not only through its information effects, but also through a direct effect, the latter arising because nominal prices do not respond in proportion to movements in money as they occur. That is to say, I would like to consider the prospects for monetary business cycle models based on some kind of nominal price rigidity. (Pages $88-89$, italics in the original.)

Many researchers, notably King and Wolman (1996) and Woodford (2003), took up this challenge by adapting staggered price-setting assumptions that had been used in the linear rational expectations macro models. In these sticky-price models, even though all observe the change in monetary policy and would like to reset prices, cannot do so because of the frictions inherent in the model. This assumption is consistent with both the Keynesian and Monetarist ideas about the monetary transmission mechanism that dominated the macroeconomics literature before 1980 .

The DSGE policy model has monetary policy operating with an interest rate rule. Until the late 1990s, models usually assumed the money supply was an exogenous autoregressive process.

Gavin, Keen, and Pakko (2005) show that these models cannot account for the time-series 
properties of inflation and market interest rates. The state-of-the-art policy model today is a New Keynesian DSGE model with sticky prices and Taylor-type interest rate rules. In the second section, we give a brief overview of the DSGE model that we use to analyze our two questions in the third and fourth sections.

\section{The DSGE Model ${ }^{3}$}

The model consists of a large number of identical households who value consumption and money, but dislike work. A continuum of monopolistically competitive firms produces intermediate goods using labor and capital owned by households and faces a nominal price rigidity as in Calvo (1983). A large number of identical competitive firms combine the heterogeneous intermediate goods to produce the final output, which can be used as consumption in the current period or as capital in the next period. Finally, we assume that the government implements monetary policy using a Taylor-type interest rate rule and transfers money to households in a lump-sum fashion.

\subsection{Households}

Households are infinitely lived agents who prefer consumption, $c_{t}$, and real money balances, $m_{t}$, but dislike work, $n_{t}$. Those preferences are represented by the following expected utility function:

$$
U=E_{t}\left[\sum_{j=0}^{\infty} \beta^{j} a_{t+j}\left(\ln \left(c_{t+j}\right)-\phi_{n} \frac{n_{t+j}^{1+\zeta}-1}{1+\zeta}+\phi_{m} \ln \left(m_{t+j}\right)\right)\right]
$$

where $E_{t}$ is the expectations operator at time $t, \beta$ is the discount factor which is between 0 and 1 , $1 / \zeta$ is labor supply elasticity, $\phi_{n}>0$ and $\phi_{m}>0$. The preference parameter $a_{t}$ is an aggregate demand shock that follows an autoregressive process of order one:

$$
\ln \left(a_{t}\right)=\rho_{a} \ln \left(a_{t-1}\right)+\sigma_{a} \varepsilon_{a, t},
$$

where $1>\rho_{a} \geq 0, \sigma_{a}>0$, and $\varepsilon_{a, t} \sim N(0,1)$.

Each period, households purchase consumption and investment goods, $i_{t}$, and acquire real bonds, $b_{t}$, and real money holdings, $m_{t}$. Those outlays are funded by the real value of bond payments from last period, $R_{t-1} b_{t-1} / \pi_{t}$, the real value of last period's real money balances, $m_{t-1} / \pi_{t}$, labor income, $w_{t} n_{t}$, capital rental income, $q_{t} k_{t}$, real dividends from the firms, $d_{t}$, and real lump-sum transfers from the monetary authority, $t_{t}$, where $R_{t-1}$ is the nominal interest rate from period $t-1$ to $t$, $\pi_{t}$ is the inflation rate, $w_{t}$ is the real wage, $q_{t}$ is the real capital rental rate, and $k_{t}$ is the capital stock. The following budget constraint describes the households' flow of funds:

$$
c_{t}+i_{t}+b_{t}+m_{t}=R_{t-1} b_{t-1} / \pi_{t}+m_{t-1} / \pi_{t}+w_{t} n_{t}+q_{t} k_{t}+d_{t}+t_{t} .
$$

\footnotetext{
${ }^{3}$ The model and the estimation of the error processes are explained in more detail in Gavin and Keen (2012).
} 
Households own the capital, which they rent to the firms. The capital accumulation equation is

$$
k_{t+1}=\left[1-S\left(\frac{i_{t}}{i_{t-1}}\right)\right] i_{t}+(1-\delta) k_{t}
$$

where $S(\cdot)$ is the functional form for the investment adjustment costs and $\delta$ is the depreciation rate. The investment adjustment costs, $S\left(i_{t} / i_{t-1}\right) i_{t}$, denote the resources lost in the conversion of investment to capital, which depend on how much the level of investment adjusts. Formally, the household selects values for $c_{t}, i_{t}, k_{t+1}, n_{t}, m_{t}$, and $b_{t}$ that maximize its utility, (1), subject to its budget constraint, (2), and capital accumulation equation, (3).

\subsection{Firms}

Firms are monopolistically competitive producers of differentiated goods. Specifically, firm $f$ produces its differentiated product, $y_{f, t}$, by combining its firm-specific labor, $n_{f, t}$, and capital, $k_{f, t}$, inputs with the aggregate level of technology, $z_{t}$, such that

$$
y_{f, t}=z_{t}\left(k_{f, t}\right)^{\alpha}\left(n_{f, t}\right)^{1-\alpha}
$$

where $1>\alpha>0$. The technology parameter, $z_{t}$, follows an autoregressive process:

$$
\ln \left(z_{t} / z\right)=\rho_{z} \ln \left(z_{t-1} / z\right)+\sigma_{z} \varepsilon_{z, t}
$$

where $z$ is the steady-state value of $z_{t}, 1>\rho_{z} \geq 0, \sigma_{z}>0$, and $\varepsilon_{z, t} \sim N(0,1)$. Firm $f$ 's labor and capital inputs are rented from perfectly competitive markets at the prevailing real wage, $w_{t}$, and capital rental rate, $q_{t}$, respectively. Given those input prices, firm $f$ seeks to minimize its production costs:

$$
w_{t} n_{f, t}+q_{t} k_{f, t}
$$

subject to (4).

The differentiated output of each firm is then aggregated using the Dixit and Stiglitz (1977) method to calculate total output, $y_{t}$ :

$$
y_{t}=\left[\int_{0}^{1} y_{f, t}^{\left(\epsilon_{t}-1\right) / \epsilon_{t}} d f\right]^{\epsilon_{t} /\left(\epsilon_{t}-1\right)} .
$$

The price elasticity of demand for a differentiated good, $-\epsilon_{t}$, follows an autoregressive process:

$$
\ln \left(\epsilon_{t} / \epsilon\right)=\rho_{\epsilon} \ln \left(\epsilon_{t-1} / \epsilon\right)+\sigma_{\epsilon} \varepsilon_{\epsilon, t}
$$

where $\epsilon$ is the steady-state value of $\epsilon_{\mathrm{t}}, 1>\rho_{\epsilon} \geq 0, \sigma_{\epsilon}>0$, and $\epsilon_{\varepsilon, t} \sim N(0,1)$. Each differentiated good, $y_{f, t}$, sells at a price $P_{f, t}$. Cost minimization on the part of households implies that the demand schedule for $y_{f, t}$ is a decreasing function of its relative price:

$$
y_{f, t}=\left(\frac{P_{f, t}}{P_{t}}\right)^{-\epsilon_{t}} y_{t},
$$


where $P_{t}$ is a nonlinear price aggregate index of a continuum of differentiated goods:

$$
P_{t}=\left[\int_{0}^{1} P_{f, t}^{\left(1-\epsilon_{t}\right)} d f\right]^{1 /\left(1-\epsilon_{t}\right)}
$$

The price-setting behavior of firm $f$ is based on Calvo (1983) with static indexing. In each period, the probability that firm $f$ can select a new price, $P_{t}^{*}$, is $(1-\eta)$, while the probability that it can raise its price only by the steady-state inflation rate, $\pi$, is $\eta$. When a price-setting opportunity exists, firm $f$ selects a price, $P_{t}^{*}$, which maximizes the present value of expected future profits to the households given the probability of future adjustment opportunities:

$$
\max _{P_{t}^{*}} E_{t}\left[\sum_{j=0}^{\infty} \beta^{j} \eta^{j} \lambda_{t+j}\left[\left(\pi^{j} P_{t}^{*} / P_{t+j}\right) y_{f, t+j}-w_{t+j} n_{f, t+j}-q_{t+j} k_{f, t+j}\right]\right]
$$

subject to the firm's demand schedule, (8), and the input factor demands from the firm's cost minimization problem, (5). The value of $\beta^{j} \lambda_{t+j}$ characterizes the value of profits to households $j$ periods in the future, whereas $\eta^{j}$ represents the probability that another price-setting opportunity will not take place in the next $j$ periods. When the first-order condition for $P_{t}^{*}$ from (9) is linearized around its steady state, the following New Keynesian Phillips curve is obtained:

$$
\ln \left(\pi_{t} / \pi\right)=[(1-\eta)(1-\beta \eta) / \eta] \ln \left(\psi_{t} / \psi\right)+\beta E_{t}\left[\ln \left(\pi_{t+1} / \pi\right)\right]+\ln \left(e_{t} / e\right),
$$

where $\psi_{t}$ is the real marginal cost of producing an additional unit of output and $e_{t}$, which resembles a cost-push shock, is a transformation of the price elasticity parameter, $\epsilon_{t}$. That is, $e_{t}=$ $e_{t}=[(1-\eta)(1-\beta \eta) /(\eta(\epsilon-1))] \epsilon_{t}$, where the parameters from the shock process in $(7)$ are re-specified as follows: $\rho_{e}=\rho_{\epsilon}, \varepsilon_{e, t}=\varepsilon_{\epsilon, t}$, and $\sigma_{e}=[(1-\eta)(1-\beta \eta) /(\eta(\epsilon-1))] \sigma_{\epsilon}$.

We also consider a case of dynamic indexing in which the constrained firms adjust by last period's inflation rate rather than the steady-state inflation rate. This dynamic indexing was introduced in order to fit the time-series properties of inflation. Roberts (1997) showed that dynamic indexing can be thought of as a way to introduce some nonrational behavior in the form of adaptive inflation expectations. With dynamic indexing, the New Keynesian Phillips curve is given as

$$
\ln \left(\pi_{t} / \pi_{t-1}\right)=[(1-\eta)(1-\beta \eta) / \eta] \ln \left(\psi_{t} / \psi\right)+\beta E_{t}\left[\ln \left(\pi_{t+1} / \pi_{t}\right)\right]+\ln \left(e_{t} / e\right) .
$$

The practical difference between static and dynamic indexing for the New Keynesian Phillips curve is simply that the steady-state inflation rate in (10) is replaced by the lagged inflation rate. 


\subsection{Monetary Authority}

The monetary authority uses a generalized Taylor (1993) style nominal interest rate rule. Specifically, the monetary authority adjusts the nominal interest rate in response to percentage deviations from the steady state for the inflation rate, $\pi_{t}$, and output, $y_{t}$, such that

$$
\begin{gathered}
\ln \left(R_{t}^{*} / R\right)=\theta_{\pi} \ln \left(\pi_{t} / \pi\right)+\theta_{y} \ln \left(y_{t} / y\right)+\theta_{d y} \ln \left(y_{t} / y_{t-1}\right), \text { and } \\
\ln \left(R_{t} / R\right)=\theta_{R} \ln \left(R_{t-1} / R\right)+\left(1-\theta_{R}\right) \ln \left(R_{t}^{*} / R\right)+v_{R, t},
\end{gathered}
$$

where the variables without time subscripts are steady-state values and the policy parameters, $\theta_{\pi}$, $\theta_{y}$ and $\theta_{d y}$, are assumed to be greater than or equal to zero and $0 \leq \theta_{R}<1$, Finally, the monetary policy shock, $v_{R, t}$, follows an autoregressive process of order one:

$$
v_{R, t}=\rho_{v} v_{R, t-1}+\sigma_{v} \varepsilon_{v, t},
$$

where $1>\rho_{v} \geq 0, \sigma_{v}>0$, and $\varepsilon_{v, t} \sim N(0,1)$.

\section{Equilibrium and Estimation}

The first-order conditions, identity equations, and exogenous shocks form a system of difference equations. Since all of the variables are stationary, the model converges to a steady-state equilibrium in the absence of exogenous shocks. ${ }^{4}$ The system of equations is linearized around that nonstochastic steady state and then standard techniques are utilized to obtain its rational expectations solution. ${ }^{5}$ By transforming the rational expectations solution into a state-space framework, the Kalman filter can calculate the optimal linear projection of the observed variables, which is used to obtain the sample likelihood function. Since the rational expectations solution is a function of the model's parameters, we estimate key parameters by maximizing the model's likelihood function with respect to the estimated parameters.

Our model is estimated using quarterly U.S. data on output, inflation, the nominal interest rate, and the capital rental rate over the sample period 1983:Q1-2007:Q4. ${ }^{6}$ Output is expressed as real gross domestic product in chained 2005 dollars divided by the civilian, non-institutionalized population, age 16 and over. The inflation rate is the percent change in the GDP implicit price deflator, while the nominal interest rate is the effective federal funds rate. The capital rental rate is the annualized 3-month rate of return on capital constructed in Gomme, Ravikumar, and Rupert (2011) from the National Income and Product Accounts data. Since the model assumes that all

\footnotetext{
${ }^{4}$ The nonstationary variables $P_{t}$ and $P_{t} *$ are eliminated from the model when first-order conditions from the firms' price-setting problem is transformed into the New Keynesian Phillips curve, equation (10).

${ }^{5}$ Our model is solved and estimated using the techniques embedded in the Dynare software.

${ }^{6}$ Since our model contains four sources of exogenous disturbances, estimating the model with more than four observed variables causes the covariance matrix of the data to be singular.
} 
variables move around their steady states, we eliminate the long-run upward trend in output by passing the output data through the Hodrick-Prescott filter.

We begin by setting the steady-state gross inflation rate, $\pi$, to 1.0064 , which is equal to the average 2.56 percent annual inflation rate observed in the sample period data. Since $\beta=\pi / R$ in the steady state, the discount rate, $\beta$, is set to the average ratio of the gross inflation rate to the gross nominal interest rate over the sample period, which is 0.9931 . The labor supply elasticity, $1 / \zeta$, is set to 3 , while $\varphi_{n}$ is selected so that the steady-state value of labor, $n$, is $1 / 3$. We do not need to specify a value for $\varphi_{M}$ because $m_{t}$ and the first-order condition for $m_{t}$ are easily dropped from any model in which the monetary authority follows a nominal interest rate rule and money is additively separable in the utility function. Capital's share of output, $\alpha$, is 0.33 ; steady-state technology, $z$, is 1 ; and the depreciation rate, $\delta$, is set to a quarterly rate of 2.5 percent. The investment adjustment costs parameters are specified in a manner consistent with Christiano, Eichenbaum, and Evans (2005), so that investment adjustment costs are binding only on the second derivative with respect to the change in investment $\left(S(1)=S^{\prime}(1)=0\right.$ and $\left.S^{\prime \prime}(1)=2.5\right)$. The steady-state price elasticity is 6 , so that the average markup of price over marginal cost is 20 percent. In order to facilitate convergence in the maximum likelihood estimation, we assume that $\theta_{R}$ and $\theta_{y}$ are equal to zero. Lastly, the probability of price adjustment, $(1-\eta)$, is set equal to 0.25 , which implies that firms adjust their prices on average once per year. The estimated values for the remaining ten parameters are displayed in Table 1.

Table 1 Maximum likelihood estimates and standard errors

\begin{tabular}{clcc}
\hline Parameter & \multicolumn{1}{c}{ Description } & Estimate & Std. Err. \\
\hline$\theta_{\pi}$ & Policy response to inflation & 1.9211 & 0.2784 \\
$\theta_{d y}$ & Policy response to output growth & 0.3467 & 0.1018 \\
$\rho_{z}$ & Persistence of technology shock & 0.9801 & 0.0091 \\
$\rho_{a}$ & Persistence of aggregate demand shock & 0.8728 & 0.0258 \\
$\rho_{e}$ & Persistence of cost-push shock & 0.5819 & 0.0730 \\
$\rho_{R}$ & Persistence of money policy shock & 0.1586 & 0.0611 \\
$\sigma_{z}$ & Std. dev. of technology shock & 0.0077 & 0.0005 \\
$\sigma_{a}$ & Std. dev. of aggregate demand shock & 0.0045 & 0.0007 \\
$\sigma_{e}$ & Std. dev. of cost-push shock & 0.0011 & 0.0001 \\
$\sigma_{R}$ & Std. dev. of monetary policy shock & 0.0055 & 0.0005 \\
\hline
\end{tabular}

\section{Can Monetary Policy Elevate Output?}

First we ask whether, in the standard DSGE model, monetary policy can elevate output. To answer this question, we examine the response of the model to a 5 percent drop in total factor productivity (TFP). In the model, as in the early RBC models, TFP 
should be thought of as a measure of features left out of the model - not necessarily, a measure of technology. ${ }^{7}$

Our baseline case is the original (Taylor, 1993) version of the Taylor rule with no interest rate smoothing; $\theta_{R}=0, \theta_{d y}=0, \theta_{\pi}=0.5$, and $\theta_{y}=0.5{ }^{8}$ Then we examine different features of the DSGE model that are commonly found in estimated DSGE models used by policy advisors. That is, we examine the effects of assuming dynamic indexing (a form of adaptive expectations) for the firms that cannot adjust their prices optimally. We also show how the degree of price stickiness and the degree of interest rate smoothing can enhance the policymaker's ability to elevate output.

In each experiment we assume a 5 percent shock to TFP. For illustration, we assume that the shock occurred in 2008:Q4 and show the Congressional Budget Office (CBO) output gap as well as the impulse response of the deviation of output from steady state to the 5 percent shock. Figure 1 shows the CBO output gap and two impulse response functions; both come from using the baseline Taylor rule. We show the case with static and dynamic indexing. The 5 percent technology shock does not explain all of the drop following the financial crisis in September 2008, but it does a good job of replicating the failure of output to rebound quickly to the steady state. Notice that the dynamic indexing does provide a bit more stabilization for output in the quarter of the shock and the quarter following, but it is offset by less stimulus over the longer run. Note that within a couple of years, the paths for output under both static and dynamic indexing converge.

The motivation for using dynamic indexing is to generate more inflation persistence and to more closely match the impulse response functions for inflation generated in structural vector autoregressions (SVARs). Figure 2 shows the inflation results for the two alternative indexing cases. Dynamic indexing smoothes the inflation response. As is the case with output, the smaller response in the first two quarters is followed by a larger response at longer horizons.

\footnotetext{
${ }^{7}$ Hall (2012) attributes the extraordinary drop in GDP in 2008:Q4 and 2009:Q1 to household deleveraging, but that does not account for the failure of the economy to bounce back to trend. For that explanation, he turns to some other source of financial friction. In our case, the financial sector is implicit in the production function and a shock to that sector is embedded in the technology shock. In an empirical study, Stock and Watson (2012) investigate the cause of the output decline. Our point here is not to ask what caused the drop in output, but to ask what macro theory has to say about whether monetary policy can speed up a recovery to the steady state path.

${ }^{8}$ Taylor (1993) used interest and inflation at annual rates. Our interest rate is scaled at a quarterly rate and the output gap is a percent deviation in levels. Thus, in all our computations, the coefficient $\theta_{y}$ value is divided by 4 .
} 


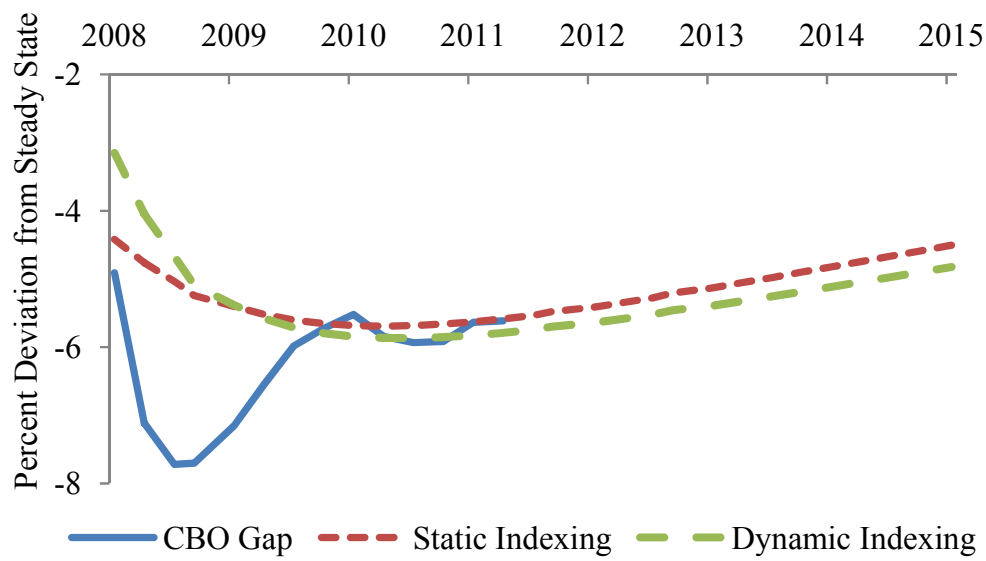

Fig. 1 Output response to a 5 percent technology shock with a Taylor rule

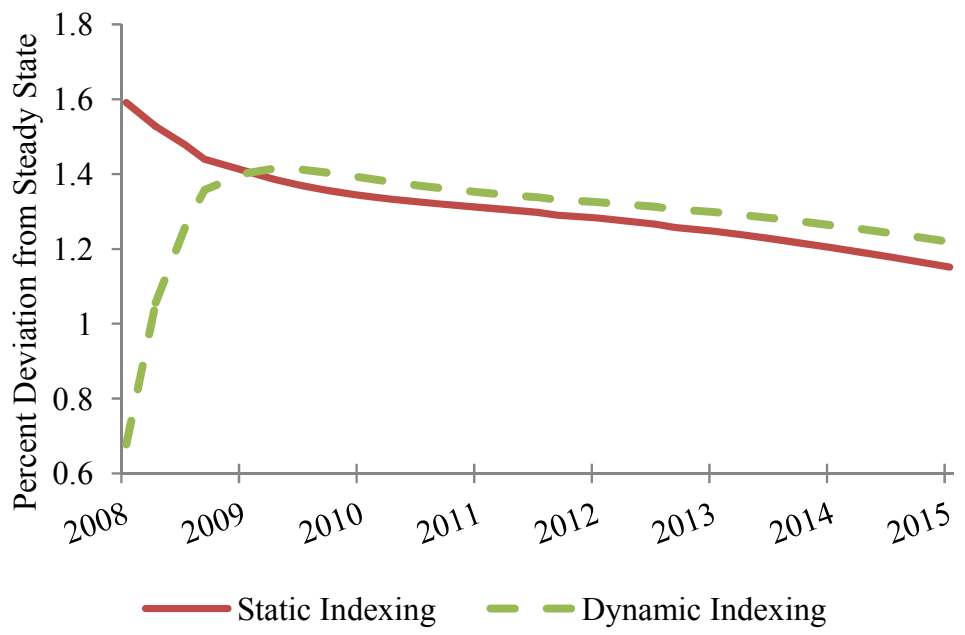

Fig. 2 Inflation response to a 5 percent technology shock with a Taylor rule

Estimated DSGE models also include interest rate smoothing $\left(\theta_{R}>0\right)$ and often find that the Calvo probability of changing prices is small. In Figures 3 and 4 we compare the impulse responses for output and inflation under these deviations from our baseline model. With either of these features, the short-run effects on inflation and output are quite different from the baseline model. With interest rate smoothing $\left(\theta_{R}=0.8\right)$, the impact effect of the technology shock is much smaller, but output falls rapidly to match the baseline case. With very sticky prices $(1-\eta=0.1)$, output is less than in the baseline case and returns to the baseline path only after three to four years.

Next we combine three features — dynamic indexing, very sticky prices, and interest rate smoothing - in order to examine the effects of alternative stabilization policies. Again, the reason for using these features is that they are common in estimated models - they help the model fit the historical time series. In Figure 5 we show three versions of the Taylor rule with these features 


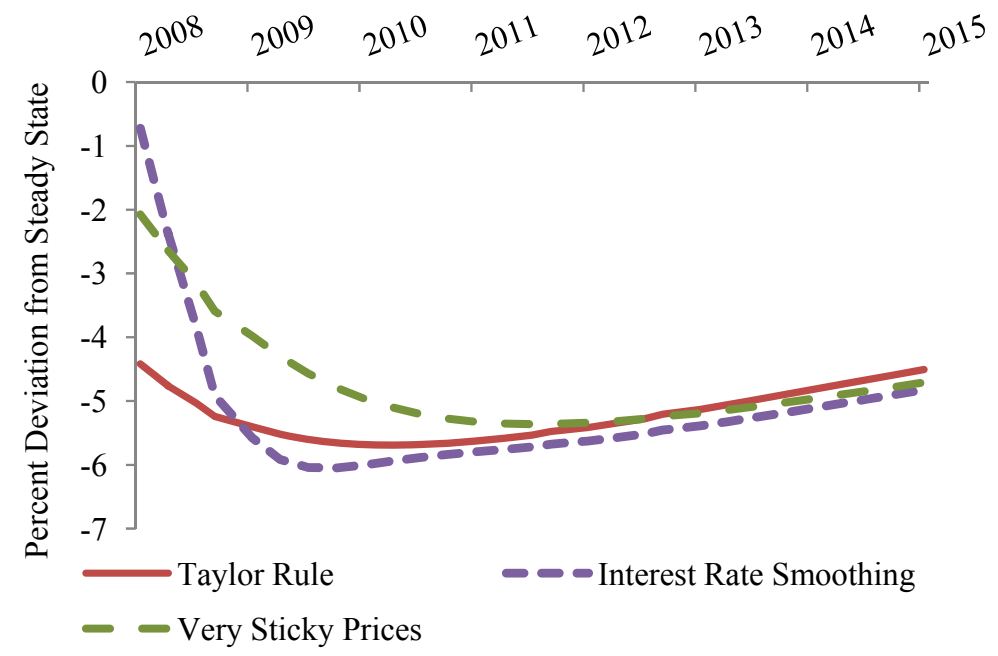

Fig 3. Output response to a 5 percent technology shock (alternative specifications)

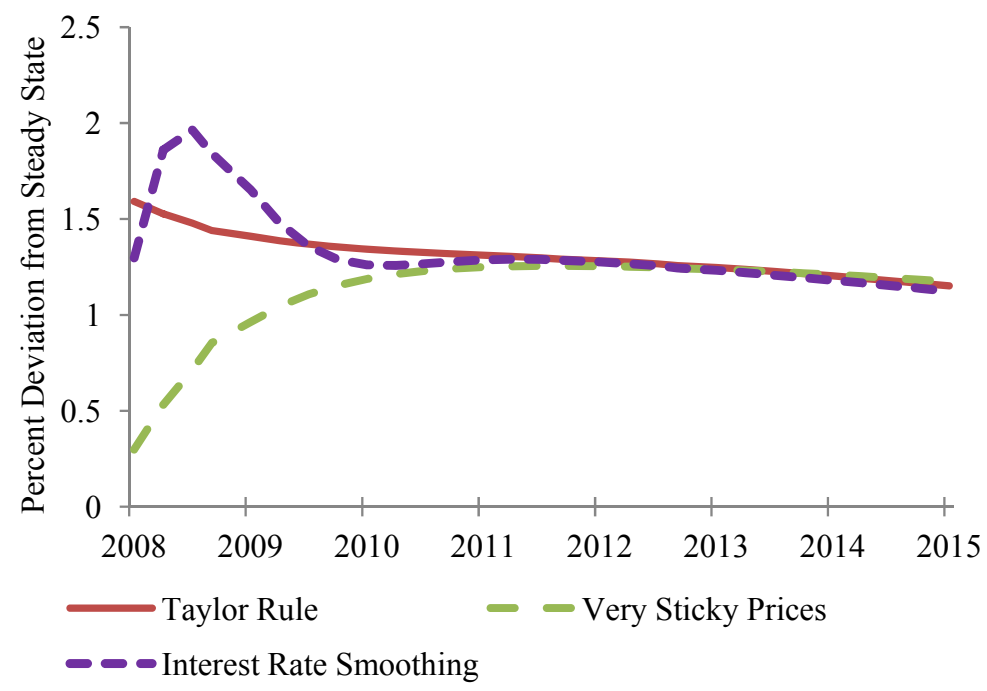

Fig 4. Inflation response to a 5 percent technology shock (alternative specifications)

included. The versions of the Taylor rule are distinguished by the weight on output. We consider the baseline rule $\left(\theta_{y}=0.5\right)$, the Taylor (1999) rule $\left(\theta_{y}=1\right)$, and a very aggressive Taylor rule $\left(\theta_{y}=2\right)$. In terms of relative weight on output and inflation gaps, the Taylor (1993) rule puts equal weight on output and inflation, the Taylor (1999) rule puts double weight on output, and our very aggressive rule puts 4 times as much weight on output as on inflation gaps.

Figure 5 shows that when we combine these three features with the original Taylor rule coefficients, we find that output is unchanged in the period of the shock. As the policymaker becomes more aggressive, output actually rises with the shock. The reason can be seen in Figure 6, which shows how inflation reacts under the alternative regimes. In each case, to get higher output 


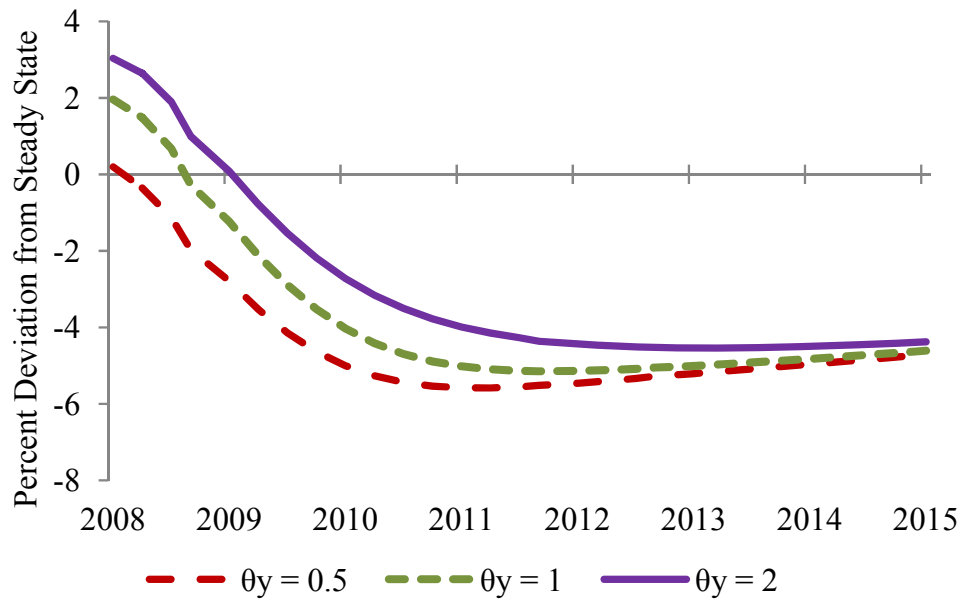

Fig 5. Output Response with Dynamic Indexing, Interest Rate Smoothing, and Very Sticky Prices

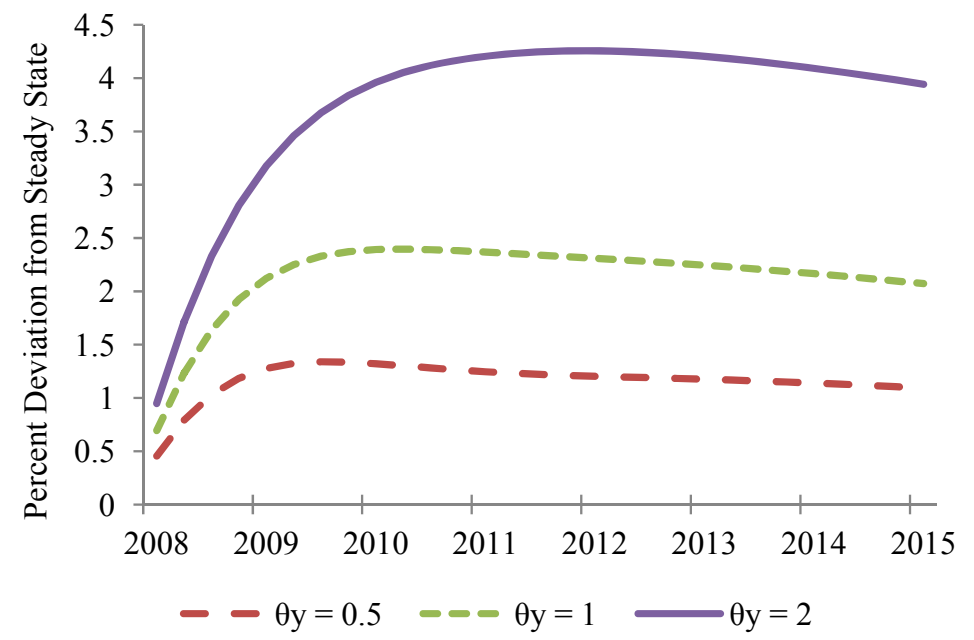

Fig 6. Inflation Response with Dynamic Indexing, Interest Rate Smoothing, and Very Sticky Prices

in this model requires a tradeoff with higher inflation. The most aggressive Taylor rule generates the most output in the short-run, but only at the expense of higher inflation. Note that in this model, the higher inflation is also associated with higher real marginal costs and lower welfare for the representative household. Figure 7 shows the deviation of real marginal costs from the steady state. The policy rule that has the largest effect on output also generates the highest real marginal costs and the lowest welfare. 


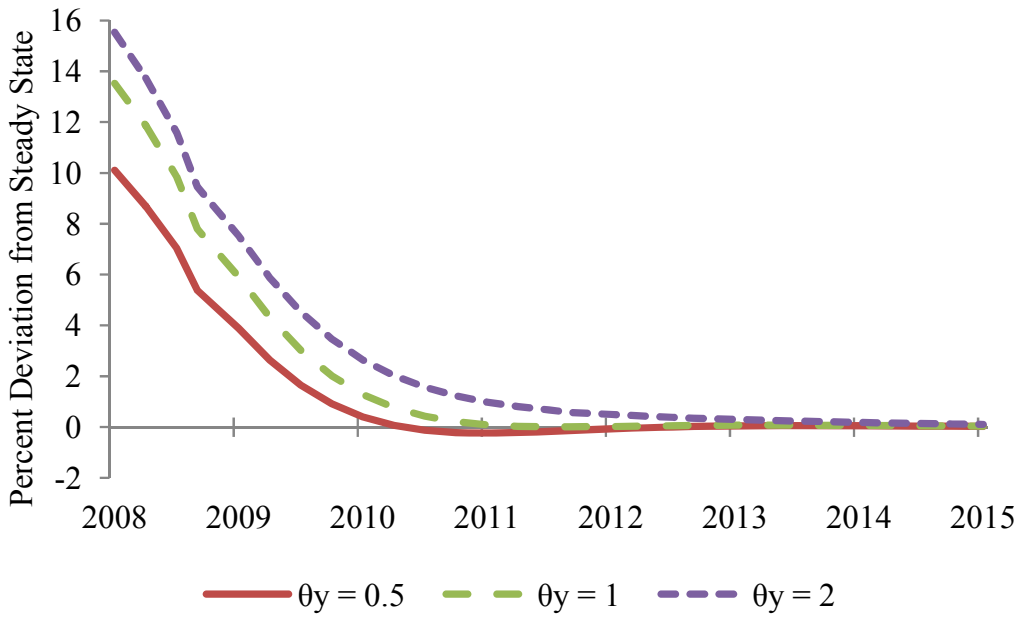

Fig 7. Real Marginal Costs with Dynamic Indexing, Interest Rate Smoothing and Very Sticky Prices

\section{Is the Zero Lower Bound a Trap?}

This section discusses some reasons why it might be difficult to raise the policy rate in the future. Figure 8 shows a 25 -year history of two U.S. interest rates: the red line shows the yield on 10-year U.S. Treasury bonds and the blue dashed line shows the federal funds rate - the overnight interest rate on bank reserves (deposits of commercial banks and thrifts at the Federal Reserve). There are three distinct patterns in interest rates after 1987 that were not there in earlier times. First, both long and short rates are trending downward throughout the period. Long-term inflation expectations fall to 3 percent in the early 1990 s and to 2 percent by the 2000 s. Second, the federal funds has traded, on average, more than 1 percentage point below the 10 -year rate. Third, the Fed holds the policy rate very low well into recoveries without any higher inflation.

There are two senses in which the Fed may be in a trap. The first one is the traditional liquidity trap, "pushing on a string." The idea is simply that adding more liquidity will not help the U.S. economy. We have gone from a situation in 2008:Q4 of liquidity crisis in which we saw a bank run on repos to a situation today in which banks and nonfinancial corporate firms are flush with liquidity. ${ }^{9}$ With the nominal interest rate at zero, people have the option of holding currency. For example, in the case of a double log money demand function, the demand for money becomes infinite as the interest rate approaches zero. In recent U.S. history, it is not clear whether adding more liquidity has done anything to stimulate investment or consumption spending.

\footnotetext{
${ }^{9}$ See Gorton and Metrick (2010) for a description of this run on repurchase aggreements (Repos).
} 


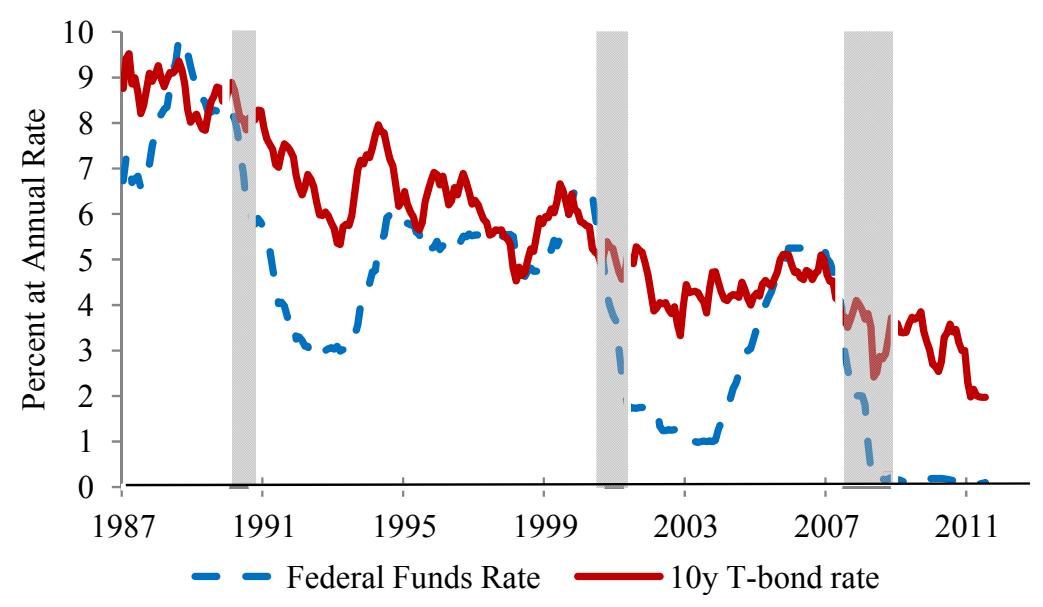

Fig. 8 U.S. Interest Rates

There is another sense in which monetary policy may be in a trap. To see this, consider a simplified version of the first-order condition for optimal bond holding in a representative household:

$$
R_{t}=E_{t}\left[\frac{1}{\beta} \frac{u^{\prime}\left(c_{t}\right)}{u^{\prime}\left(c_{t+1}\right)} \pi_{t+1}\right]
$$

With log utility, the stochastic discount factor (SDF) becomes $(1 / \beta)\left(c_{t+1} / c_{t}\right)$. Figure 9 shows the real federal funds rate (calculated as the nominal federal funds rate minus the year-over-year percentage change in the PCE chain price index) and an estimate of the stochastic discount factor calculated using per capita real consumption on services and nondurables. For this calculation, we calibrate the discount factor to 0.994 so that the average SDF is approximately equal to average real federal funds rate.

The SDF is the real interest rate implied by households' choice of the path for consumption. Here, it is taken as a reasonable measure of a neutral real interest rate. The idea is that adjusting the nominal interest rate point for point with changes in this real interest rate will tend to keep monetary policy neutral, eliminating net stimulus. Using the SDF as a measure of the appropriate real rate, the real federal funds rate was too high leading up to and during the 1991 recession, too low in the recovery that followed, and too low again in the recoveries following the 2001 and 2008 recessions. Note, however, that the long period of negative real consumption growth during 2008 and early 2009 was associated with a very negative SDF and justifies the decision to go to the zero lower bound in 2008:Q4. However, as the economy and consumption started to grow, the SDF indicates that the real federal funds rate is again too low by the middle of 2010 . 


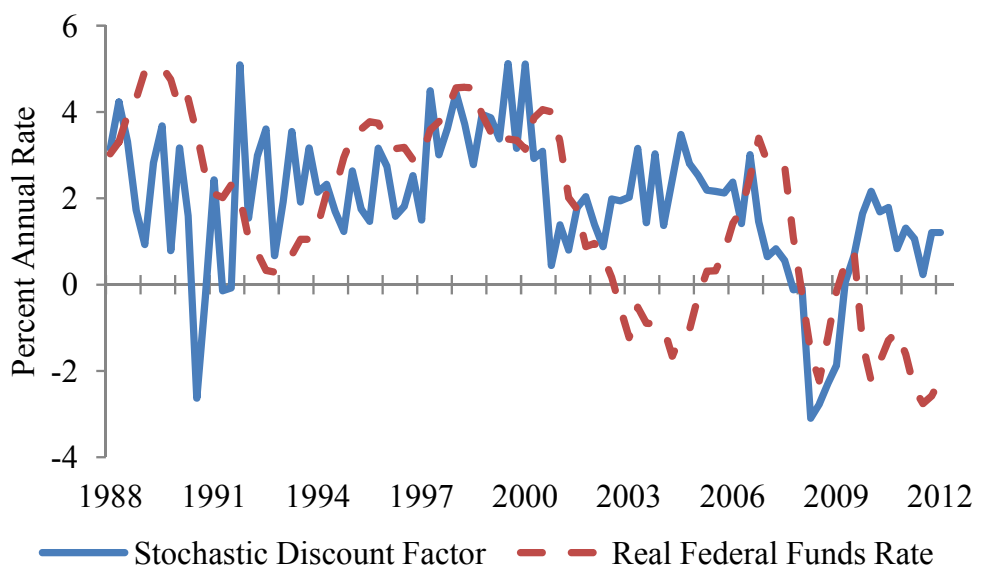

Fig. 9 The real interest rate and stochastic discount factor

What will happen if the Fed keeps the policy rate near zero for an extended period? We can use the Fisher equation to think about this issue. Consider two alternatives. First, suppose, as do Benhabib, Schmitt-Grohé, and Martin (2001) or Gallmeyer et al. (2007), that the real interest rate is determined by real factors and is independent of the Fed's monetary policy rule. Then holding the interest rate at zero in a DSGE model will tend to drive inflation lower, not higher. When the nominal interest rate is fixed, inflation adjusts to clear the bond market. It is determined in the model by a "Fisher equation" that is derived from the first-order condition for nominal bonds, the first-order condition for capital, and the interest rate rule. The Fisher equation states that the nominal interest rate is equal to the real interest rate plus the expected inflation rate. The Fisher equation also determines inflation in a sticky price model, but both inflation and the real interest rate are temporarily distorted by the parameters that define the nominal rigidity. ${ }^{10}$

The Fed has used LSAP and forward guidance as unconventional tools to keep inflation from falling. For the second alternative, we assume that the Fed keeps the inflation rate at a fixed 2 percent target rate. Then the zero nominal rate must be associated with a negative real rate. Keeping the real rate negative for an extended period implies that, somehow, the zero rate policy causes people to converge to an equilibrium with low real rates which, on reflection, are likely to be associated with low real growth. The problem is there is no widely accepted macro theory that can explain how monetary policy can directly affect the real rate over a long period in this way. This may explain why there is a surge of interest in business cycle models in which output can be dampened by policy uncertainty. ${ }^{11}$ Research economists are searching for models that can explain a recovery with low real output growth, a low labor participation rate, and a high unemployment rate.

From a practical perspective, the zero interest rate bound may be a trap because policymakers tend to look at the Phillips curve when deciding how to set the federal funds rate. Under the first alternative assumption with a fixed nominal rate, a rise in real interest rates as the economy

\footnotetext{
${ }^{10}$ See Sustek (2011), who derives this Fisher relationship and the driving process for inflation in a New Keynesian model.

${ }^{11}$ See, for example, the work of Bloom (2009) and Baker, Bloom, and Davis (2012).
} 
recovers will tend to make inflation fall. If inflation is falling and the economy remains short of full employment, the Taylor rule recommends a lower interest rate. Since the Federal Reserve cannot lower the rate below the zero lower bound, it can only simulate the lower nominal rate with LSAP and more forward guidance. This is reminiscent of policy in Japan in the 1990s. The longer the Bank of Japan held the overnight rate at zero, the lower inflation fell and the lower bond yields fell. Eventually, people stopped forecasting higher inflation and interest rates. The Japanese economy appears to have converged to a Friedman-like equilibrium with short-term rates at zero, government bond yields at 1 percent, and a slight deflation. The Japanese people and their government have adapted to being at the ZLB by accepting slight deflation as a policy objective.

Under the second alternative in which there are two equilibria, one with high interest rates and high real output growth, the other with low interest rates and low real output growth, promising to keep the rate at zero for an extended period may only serve to keep the economy in a low growth equilibrium. ${ }^{12}$ If real growth is slow and inflation is at the target rate, then the Fed's dual mandate - to both stabilize inflation and maintain full employment — will lead policymakers to keep the interest rate near zero indefinitely.

\section{Conclusion}

In this paper we ask two questions: Can monetary policy elevate output and is the zero lower bound a trap? We review some basic concepts in modern macro theory and use a standard New Keynesian DSGE model to answer the first question. The model shows that the central bank can influence the path of output following a shock. There is a short-run tradeoff between output and inflation. Specifications of the model that include a very large reaction to output shocks, some interest rate smoothing, very sticky prices, and some adaptive expectations mitigate the effect of negative shocks on output. But they elevate output by raising inflation, real marginal costs, and welfare losses. In the standard DSGE model, it is not welfare enhancing to adopt short-run policies that trade more inflation for more output.

Macroeconomic theory predicts that the optimal path for output (potential output in the model) will be time varying and not the smooth path generated using statistical filters or the even the more sophisticated CBO methods. Yet, the actual loss functions used to evaluate policy typically penalize policies that allow output to deviate from these smooth paths. Why do central banks analyze policy in models that ignore the lessons we have learned about the importance of assuming rational, optimizing agents when doing counterfactual policy simulations? Partly, it is because policymakers understand that all models are merely stylized representations of reality. To be useful, models must be relatively small and tractable; therefore, they must necessarily be false on many dimensions. They also understand that a particular derivation of optimal policy is highly model dependent and that there are important differences of opinion about which models are most useful.

${ }^{12}$ For a summary of these ideas, see Bullard (2010). 
The appearance of disagreement, however, is greater than the reality. Most differences in methods and model specification reflect differences in the questions to be addressed. Academic economists are eager to tell policymakers what they should do, and central bank economists are more likely to ask policymakers what they want to do. Most of these policymaker questions involve understanding the state of the economy, which requires a large model that collates and classifies a wealth of incoming economic information. Policymakers want to know what the state of the economy will be tomorrow and next year. So the emphasis for central banks is on forecasting and understanding the state of the economy.

One consequence of the focus on forecasting is that models used to perform counterfactual policy simulations in policy briefings will be required to fit the data. ${ }^{13}$ See, for example, two DSGE models that are used within the Federal Reserve to do forecasting - the EDO model documented in Chung, Riley, and LaForte (2010) and the PRISM model documented by Sill (2009) - have elements of adaptive inflation expectations, sticky prices and relatively high interest rate smoothing. These features are included because they help the model fit the data. When policymakers ask, "Can the Fed elevate output?" the answer is provided by such models. Policymakers rarely ask questions about social welfare or real business cycle effects implied by the models. The decision to base counterfactual policy evaluation on models designed to forecast well is a decision to set aside, or at least to deemphasize, the lessons learned in the rational expectations and RBC literatures.

The answer to the second question depends on monetary policy. Under the Fed's current policy rules, it is difficult to predict a likely situation in which the policy rate is raised. Can policy affect the real interest rate over longer horizons? If not, then maintaining the nominal rate at zero for an extended period will tend to cause deflation if the real economy and real interest rates recover. If the central bank policy can affect the equilibrium real interest rate and there are multiple equilibria as discussed in Bullard (2010), then it may be that choosing to keep the nominal rate at zero causes the economy to coordinate on a low real interest rate, low output growth equilibrium. But such a mechanism has not been worked out in theory.

\footnotetext{
${ }^{13}$ See Kocherlakota (2007) for an analysis of using 'fit' as a criterion for specification choice in policy models.
} 


\section{References}

Adam K, Billi RM (2006) Optimal monetary policy under commitment with a zero bound on nominal interest rates. J Money Credit Bank. 38(7): 1877-1905

Adam K, Billi RM (2007) Discretionary monetary policy and the zero lower bound on nominal interest rates. J Monet. Econ. 54: 728-732

Baker S, Bloom N, Davis S (2012) Has economic policy uncertainty hampered the recovery? George J.Stigler Center for the Study of the Economy and the State, Working Paper No. 242, February 3, 2012.

Benhabib J, Schmitt-Grohé S, Uribe M (2001) The perils of Taylor rules . J Econ. Theory. 96: 4069

Bloom N (2009) The impact of uncertainty shocks. Econometrica. 77(3): 623-685

Braun RA, Körber LM (2011) New Keynesian dynamics in a low interest rate environment . J Econ. Dyn. Control. 35(12): 2213-2227

Braun RA, Körber LM, and Waki Y (2012) Some unpleasant properties of log-linearized solutions when the nominal rate is zero. Federal Reserve Bank of Atlanta Working Paper 2012-5.

Bullard J (2010) Seven faces of 'the peril'. Fed. Reserve Bank St. Louis Rev.. 92(5): 339-352

Calvo GA (1983) Staggered prices in a utility maximizing framework . J Monet. Econ. 12(3): 383398

Christiano LJ, Eichenbaum M, Evans CL (2005) Nominal rigidities and the dynamic effects of a shock to monetary policy. J Polit. Econ.. 113(1): 1-45

Chung, Hess T., Michael T. Kiley, and Jean-Philippe Laforte. (2010) Documentation of the estimated, dynamic, optimization-based (EDO) model of the U.S. economy: 2010 Version, Board of Governors, Finance and Economics Discussion Series 2010-29.

Eggertsson GB, Woodford M (2003) Zero bound on interest rates and optimal monetary policy. Brook. Pap. Econ. Act. 1: 139-233

Gallmeyer MF, Hollifield B, Palomino FJ, Zin SE (2007) Arbitrage-free bond pricing with dynamic macroeconomic models. Fed. Reserve Bank St. Louis Rev.. 89(4): 305-326

Gavin WT, Keen BD (2012) The zero lower bound and the dual mandate. Fed. Reserve Bank St. Louis Working Paper 2012-026A

Gavin WT, Keen BD, Pakko MR (2005) The monetary instrument matters. Fed. Reserve Bank St. Louis Rev. 87(5): 633-658

Gomme P, Ravikumar B, Rupert P (2011) The return to capital and the business cycle. Rev. Econ. Dyn.. 14(2): 262-278

Gorton G, Metrick A (2010) Haircuts. Fed. Reserve Bank St. Louis Rev.. 92(6): 507-520

Holden T, Paetz M (2012) Efficient simulation of DSGE models with inequality constraints. University of Hamburg, manuscript, June 2012.

King RG, Wolman AL (1996) Inflation targeting in a St. Louis model of the 21 st century. Fed.

Reserve Bank St. Louis Rev.. 78(6): 83-107

Kocherlakota N (2007) Model fit and model selection. Fed. Reserve Bank St. Louis Rev.. 89(4): 349-360 
Kydland FE, Prescott EC (1982) Time to build and aggregate fluctuations. Econometrica, 50(6): 1345-1371

Lucas RE Jr (1987) Models of business cycles. Basil Blackwell, New York

Sill K (2011) Technical appendix: PRISM model documentation," Manuscript.

http://www.philadelphiafed.org/research-and-data/real-time-center/PRISM/PRISMtechnical-appendix.pdf

Sustek R (2011) Monetary business cycle accounting. Rev. Econ. Dyn.. 14: 592-612

Taylor JB (1999) A historical analysis of monetary policy rules. In: Taylor JB (ed) Monetary policy rules. University of Chicago Press, pp 319-348

Taylor JB (1993) Discretion versus policy rules in practice. Carnegie-Rochester Conf. Ser. Public Policy. 39(1): 195-214

Woodford M (2003) Interest and prices: foundations of a theory of monetary policy. Princeton University Press, Princeton NJ 